\title{
Holistic Picture of Socio-economic Development: Endogenous and Exogenous Nature of Cycling
}

\author{
Iryna M. Kaparulina ${ }^{1, *}$ \\ ${ }^{1}$ National Aviation University, Kiev, Ukraine \\ *Correspondence: Kosmonavta Komarova ave, building no. 2, Kyiv 03058, Ukraine \\ E-mail: kaparulina@outlook.com
}

Received: June 11, 2013 Accepted: July 8, 2013 Published: July 25, 2013

doi:10.5296/rae.v5i3.3845 URL: http://dx.doi.org/10.5296/rae.v5i3.3845

\begin{abstract}
The paper discusses the study of nature of cycling of socio-economic changes and is focused on coordination of fragmentary concepts of development of various fields of human activity. Taking into account multidisciplinary nature of this paper, the study was carried out using qualitative research methods. The article offers the concept of economics and society evolution in the form of a holistic picture of socio-economic changes, where public worldview is an endogenous evolution factor, and solar activity is an exogenous factor. Socio-economic changes from the middle of $17^{\text {th }}$ century to the present day are described in the form of eight successive stages of a large evolutionary cycle (400-440 years). Presented concept is based on a poly-objective approach of evolution of Being, therefore social and economic development is treated as a natural part of the process of Universal Evolution. Generality of the proposed evolution concept makes it possible to use it in other fields of knowledge.
\end{abstract}

Keywords: structural change; social interaction; causal mechanism; globalization; history 


\section{Introduction}

Evolution, both of people and organizations, depends on their successful adaptation to environment. That said, adaptation nature changes from passive response to environmental changes towards their prediction (for the purpose of implementation of preventive actions) to active influence on environment.

A wide range of research papers deals with identification and forecasting of trends in economics development. However, taking into account mixed character of human activity resulting in integration of economic, cultural, political spheres of public life, studies considering demonstration of public life as a whole are of interest for us. In such a case, two main problems solved in such studies can be distinguished:

- determination of evolution goal: stages of growth of W. Rostow (1960), agricultural, industrial and post-industrial society of D. Bell (1999), J. Fourastie (2001) etc.;

- identification of cycling factors: cycles of the conjuncture of N. Kondratiev (2002), innovative cycles of J. Schumpeter (1939), technological modes of S. Glazyev (1993) etc.

However, in our view, perspective of identification of economic trends has to be formed with due consideration of:

- regular and situational nature of changes characterizing evolution process, which assumes limitation of range of changes variation in development of any being object by its functional purpose;

- universal forms of development of being - divergence and convergence, determining polyphonic character of evolution: availability of several parallel trends, which gradually integrate, interlace and then separate again;

- conceptual coherence of purpose and periodicity of changes as fundamental properties of any process.

Therefore, a holistic concept of economic and social development must be substantiated, where purpose of changes would be visible against cyclical fluctuations, and economic changes would be considered as a natural component of social changes. Such presentation of a problem assumes determination of driving forces for society development with endogenous and exogenous nature.

\section{Preconditions of the Research}

This research is based on the hypothesis according to which, beginning from the middle of XVII century - period of the English Revolution, which gave an impulse to industry development in Europe - up to the present day social changed are determined by development of economics, which is related to transition of mankind to practical transformation of environment. Therefore, we took the middle of XVII century as a starting 
point in analysis of social and economic changes.

Definition of stages in economics development is a procedure based, as a rule, on processing of statistical array of indices. Its difficulties include, primarily, finding wave fluctuations against the background of trend and exclusion of influence of random factors. However, focus on the use of statistical methods, in our view, results in a significant error in view of:

1) use of indices with claims to their calculation, due to their inaccurate reflection of corresponding economic events (for example, GNP);

2) accounting of total value of indices change without distinction of influence of system and specific factors of changes;

3) difficulties in separation of latent and visible evolution phases;

4) not taking into account qualitative character of changes.

Apart from limitations related to application of statistical research methods, multidisciplinary character of this paper assumes implementation of a set task in the form of fusion of heterogeneous information, i.e. data conveying different meanings, which provides for associative character of conceptual relations. The listed arguments predetermine qualitative character of research. Therefore, at determining of driving force for development of economics and society we took into account the following scientific facts indicating multidimensionality of cyclic events in human life:

First, wave transformation of social and economic processes with duration of periods approximately 55 years statistically proved by N. Kondratiev (2002);

Second, study of cycling of historical events in human progress (Modelski, 2005a, 2005b; Lapkin, 2010; Braudel, 2007);

Third, statistically valid economic cycles with duration of 9-11 years and 20-25 years Juglar, 1862; Kuznets, 1930);

Fourth, a hypothesis for influence of the Sun on behavior of social groups substantiated by A. Chizhevsky and later confirmed by other authors in the form of theory o influence of sunspot 11-year cycles on social and economic, political processes of society and on natural processes on Earth (Chizhevsky, 1924, 1976; Belkin \& Yahontov, 2011; Vladimirovsky, 2004);

Fifth, study of economic development of countries of A. Maddison, indicating existence of a certain development path of three groups of countries (Maddison, 2005);

Sixth, innovative concept of cycling of economic events indicating relation between innovations and social changes (Schumpeter, 1939);

Seventh, a hypothesis for reduction of duration of cycles of the conjuncture (Glazyev, 1993);

Eighth, concept of spiral dynamics of Graves (2005).

At forming of application part of the research - specification of stages of social and economic development - works of economics history, general history and philosophy served as a data base. 


\section{MlMacrothink}

\section{Endogenous Development Factor}

As a result of logical and intuitive reasoning we acknowledged world view as an internal driving force stipulating cyclic changes in society, as all expressions of human activity bear the impress of people's understanding the world and their place in it: target selection, means for its achievement, estimation criteria and interpretation of events of reality. According to H. Blumer (1984), people interact with each other based on the meaning they put into image of being, but at the same time meaning is also formed under the influence of social interactions resulting in change of world view. Taking into account ambiguity of the concept "world view", for the purpose of this research it shall mean a relatively stable (not of situational character) individual's concept of the world formed based on its internal organization related to its way of obtaining and processing, estimation and generalization, structuring and systematizing, transformation and use of information, displayed in its behavior.

In our view, the primary factor is that an individual hereditarily (genetically) receives only qualitative characteristics determining its mode of existence, but not knowledge - "tabula rasa" as a principle of human brain structure (Locke, 1985, p. 154-168). This stipulates novelty of perception of the world by human and, consequently, formation of new ideas. As a result, cycling of human existence is stipulated by attitude of people towards changes and alternation of generations, and heritability, progress of the process of social changes - by upbringing and education, whereby stored knowledge and experience are transferred.

In Figure 1 a principle diagram of formation of social and economic development cycle is show as a result of entry of current change wave into force against the background of previous dying change wave - change of world view waives. Pattern of a change wave is S-shaped (diffusion diagram). The period during which percent of people involved in this process amounts to approximately $10 \%$ [critical mass according to (Xie et al., 2011)] is considered to be implicit phase of a change wave. Taking into account dying character of a wave of previous changes with simultaneous entry of a wave of further changes into force and self-sustaining character of other waves, we consider the moment of involvement of approximately $20-25 \%$ of society in current changes to be the peak of cycles of the conjuncture. As a result, general view of the process of society development can be presented as interlacing without loss of independence of world view waives having character of a self-sustaining chain reaction with consistent predominance of each wave, which is described by V. Pareto $20-80$ rule in statistics. 


\section{Macrothink}

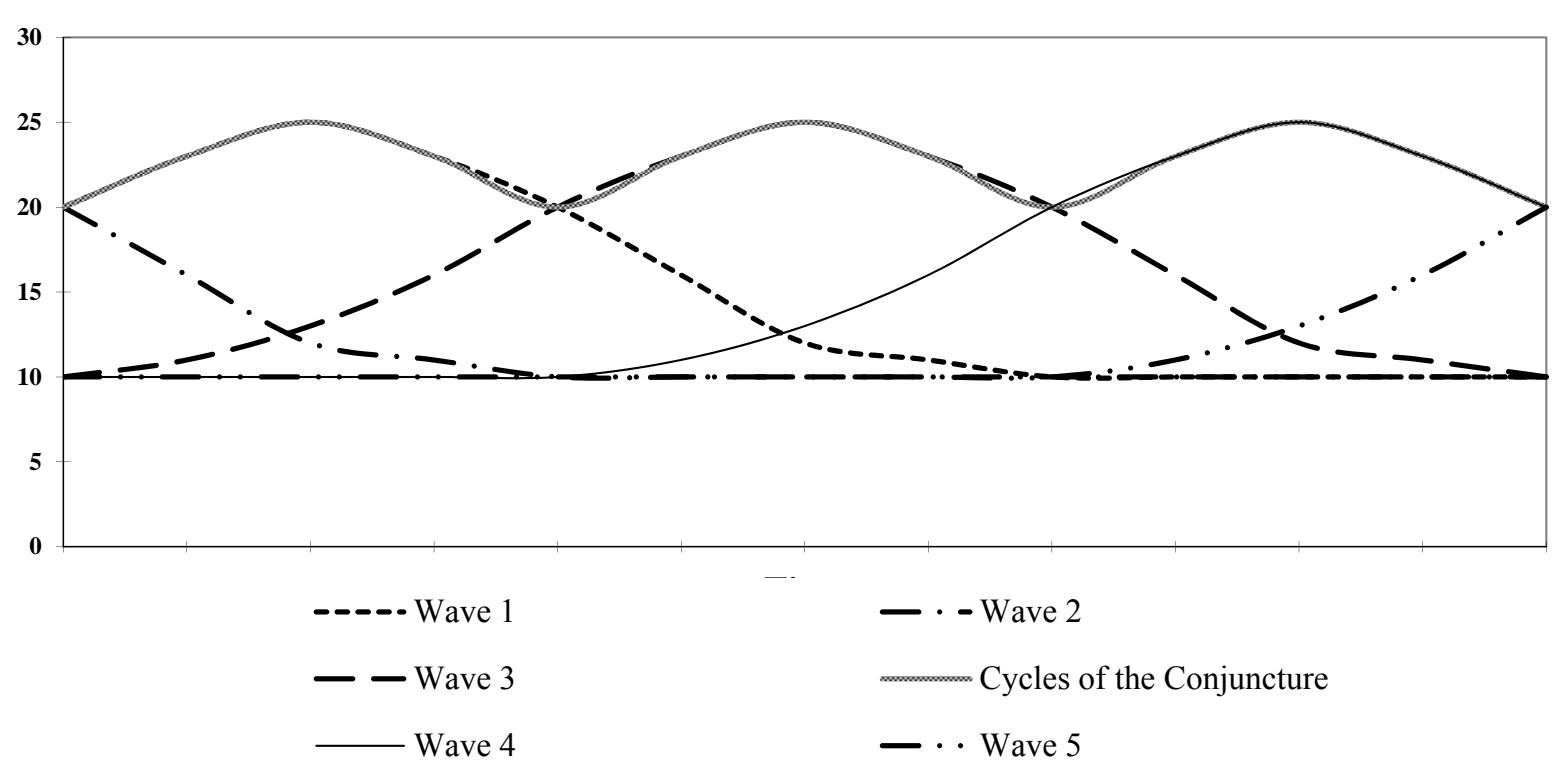

Figure 1: Principle Diagram of Formation of Socio-economic Development Cycle

In spite of progress of development, with increase of scale of the social changes process due to current heterogeneity of social elements we can observe unevenness of development with revolutionary character of changes in so called "narrow space". In other words, we consider the purpose of social development as a result of complication of human society due to harmonization of its internal contradictions - "combination of diverse and coordination of inconsistent" [by Philolaus (Sokolov, 1969, p. 289)]. Therefore, the world view is an endogenous factor of society development.

\section{Exogenous Development Factor}

Taking into account that functioning of the whole needs synchronization of actions of its components, and treating human society and its activities (including economics) as a natural part of natural ecosystem of the Earth and Solar system, we consider sunspot activity to be an exogenous factor of human society development. In other words, we consider cycling phenomenon as a result of hierarchical pattern of existence structure (Pavlenko, 2011): consistency and synchronization of the interaction of elements of any complex object is achieved by conformity of functioning pace of elements of the lower level of hierarchy with the pace of more complicated element (subsystem) of the next level of hierarchy, which components they make. We consider that within such time period as millennium duration of social development cycles concerning all fields of human activity remains unaffected. Therefore, having critically examined arguments for reduction of duration of cycles of the conjuncture, principle of uniformity of cycle progress became the basis of our concept of society evolution.

Influence of sunspot cycles on the cycling of changes in social life is demonstrated by means of complex influence on natural processes on Earth (provoking certain chemical reactions): earthquake, flood, disease and death rate of people, etc., including increase of human activity. 
A range of statistical studies indicating rate of duration cycles of the conjuncture and duration of sunspot cycles and cycles of C. Juglar and S. Kuznets, as well as results of research of sunspot cycles influence on life on Earth and research of historical events enables us to take 50-55 years as duration of social development factor. At a later stage, such assumption was confirmed during specification of the stages of social and economic development.

Analyzing difference of opinion of various researchers regarding determination of calendar periods of cycles of the conjuncture (Kondratiev, 2002; Rostow, 1960; Bell, 1999; Lapkin, 2010; Belkin \& Yahontov, 2011), we arrived at the conclusion that they are explained by:

First, binding of social changes to the peak or decrease in sunspot activity as a starting point in11-year cycle (D’Aleo, 2008),

Second, selection of a certain sunspot cycle as a starting point in 55-year cycle.

Regarding the first reason for contradiction we think that as universal process of changes is described by s-shaped function, decrease in sunspot activity must be considered as a starting point in11-year cycle. Regarding the second reason: in our opinion, such difference in calendar periods is connected with excessive binding to statistical figures during cycle division. However, formation of a holistic picture of changes shall be subject to a certain idea reflecting the spirit of time which concerns all fields of life including economics (taking into account different level of sophistication of various fields of human activity). That said, the picture of expressions can only have essential resemblance, as the process of changes is purposeful, irreversible, which excludes frequency of occurrence.

\section{Characteristic of the Stages of Social and Economic Development}

So, taking into account conceptual orientation of public processes and the forgoing provisions based on a poly-objective approach which principles are stated in (Kaparulina, 2012a, 2012 b), by our assumptions the period from 1656 to approximately 2092 is era of society development related to dynamic economics development which includes eight stages:

1) technologic stage $(1656-1711)$,

2) institutional stage $(1711-1766)$,

3) entrepreneurial stage (1766 - 1823),

4) conventional stage $(1823-1878)$,

5) organizational stage (1878 - 1933),

6) communication stage (1933 - 1986),

7) strategic stage (1986-2039),

8) synthetic stage $(2040-2092)$.

Eight stages distinguished by us can be considered as a universal structure of a large cycle of 
social development (400-440 years) during which society acquired a certain property and fixed it at the integral level. Each development stage corresponds to domination of a definite wave of world view in society, which is shown in table 1 (described in detail in (Kaparulina, 2012 b)).

Table 1: Characteristic of Worldview Types

\begin{tabular}{llllll}
\hline Period & Worldview & Outlook & Motivation & Feature & Behavior type \\
\hline Technologic & Consumer & $« \mathrm{I} »$ & Self-preservation & Egocentrism & Use \\
Institutional & Formalistic & Family & Self-reproduction & Formalism & Coexistence \\
Entrepreneurial & Competitive & Community & Self-affirmation & Domination & Competition \\
Conventional & Relativistic & Class & Self-sufficiency & Tolerance & Compromise \\
Organizational & Hierarchical & Nation & Self-organization & Orderliness & Collaboration \\
Communication & Systemic & Society & Self-improvement & Openness & Cooperation \\
Strategic & Transformational & Humanity & Self-activation & Empathy & Complimentarily \\
Synthetic & Holistic & World & Self-programming & Harmony & Interdependence \\
\hline
\end{tabular}

Let us describe the foregoing stages in details, regarding changes in cultural, political and economic life of society, comparing such changes with corresponding type of world view.

\subsection{Technologic Stage}

World view of this period can be called consumptive: the world is seen from "I" perspective, survival as seizure of life niche is achieved "by trial and error". Satisfaction of own needs is considered as a natural state of an individual, and due to this people can harm each other (Hobbs, 1989). Scholastic gave place to empiricism; active transformation of reality replaced its passive observation. "Most great mathematicians..." from the middle of XVII century and in XVIII century, "as they were engaged in practical mechanics applying theoretical grounds to it, come from ordinary watermill for grain milling" (Podlesny, 2004, p. 43). The art of this period is focused on reflection of wide range of individual's possibilities resulting from human brain. This is expressed in hymning human's potential, use of such devices as extravagance representing challenge (heroism and grotesqueness of the baroque, and then more elegant rococo).

Characteristic feature of public life is seizure of its life niche by the bourgeois class. This process was the most striking in England: "from that time the bourgeois class became a modest but acknowledged part of ruling classes of England."(Engels, 1952, p.96) Social relations were built on exploitation and robbery, as peasant class and craftsmanship remained deprived of rights. Now craftsmen work "not directly for their buyers, but for a capitalist entrepreneur - owner who united all separate parts of manufacturing process and still supplied the market with finished goods."(Gelmolt, 1904, p.106) Occupation (social class) is a social identifier.

Europe is the center of world political actions forming trends of humankind development. Monarchs of European states have the absolute power which basis is force rather than law. Absolutism explosion is evidenced in France - Louis XVI reign. There are absolutism decline in form of Stuart' efforts to rule bypassing the Parliament in England. European states carry out the expansionist colonial policy. Colonies are the source of enrichment for metropolitan 
countries, rather than market for the goods: natural resources of colonies are spoiled and population is exploited. In result of English-Dutch wars of 50 - 70 years, French-Dutch wars of $1672-1678,1688-1697,1702-1713$ Great Britain becomes the world leader as the symbol of the industrial capital domination.

The dissipated manufacture is step by step replaced with centralized one with application of horizontal labor division. It allows separating qualified labor from non-qualified one and giving the stimulus for active use of instruments of labor. Therefore, small machine production appears within the framework of manufacture. Manufacture growth occurs at the expense of horizontal absorptions resulting in the initial capital accumulation. Thus, for the period since 1660 up to 1688 in England English industry, trade and deep-sea tonnage more than doubled (Zhukov, 1958). The protectionism is one of the important conditions of industry development in England.

\subsection{Institutional Stage}

The formalist worldview manifests itself in aspiration to regulate any manifestations in social and economic life by means of rules. Social contract as means of safety provision is the method for settlement of social discrepancies arising on the ground of violation of interests of each other: "Discourse on the Origin and Basis of Inequality among People" by J-J. Rousseau (1970, p.560-567), “The Spirit of the Laws" by Charles-Louis de Montesquieu (1955). The art have the character of traditionalism: appeal to canons, classics; the accent on the identity of people outside the hours and space.

All social life is saturated with spirit of regulation: reduction to unity of all variety of rules of law; transformation of institution of state administration from obedient instrument (as at previous power regime) into restraining force; restriction of religion intervention into government of a state. A series of engineer schools and other educational institutions with teaching of technical disciplines are established in Europe (Podlesny, 2004, p.47). The publication of "Encyclopedia" in France contributed to knowledge accessibility for great masses of population. The property is the social identifier. Hired workers often are still connected closely with their own households, they have land plots or they are owners of means of production (Zhukov, 1958).

European states retain features of absolutism, but such that is restricted by rules and regulations - educated power. The constitutional monarchy exists only in Great Britain; growth of importance of state apparatus of government is present in other states. The social opinion has considerable influence on internal life in state. Newspaper role increases in social life. The Freemasonry is spread.

Europe still sets the trend of the world development; however, European states establishing empires now not simply use colonies, but rather step by step introduce features of their social and economic relations, as well as political culture in activity of colonies. The greatest effect is present in American colonies where the united internal market is formed among colonies, as well as production of not only raw materials for metropolitan countries, but also of finished products is carried out. The complexity of government of empires contributes to 
introduction of indirect government of colonies, when without violation of absolutism basis colonies are provided with some independence. However, the consumer attitude of metropolitan countries to colonies is retained.

The institutionalization of financial and credit sphere (banking and stock activity is regulated) takes place in economy. The integration of entrepreneurial and trade activity allows extensive production growth. The mechanization and typing of manufacture activity result in cheapening of production job process. The application of mechanical clocks makes it possible to ensure the uniformity of production process.

\subsection{Entrepreneurial Stage}

The competitive worldview as the aspiration of self-assertion on the background of declaration of equal rights determines all social processes: "or-or" opposition (dualism) as the basis of linear thinking with aspiration to dominate. In everyday life it is expressed in philosophy of utilitarianism by J. Bentham (Bentham, 1834), when basing on individual interest the harassment of others takes place by means of legal methods. In scientific cognition of the world it corresponds to opposition of idealism and materialism, subjectivity and objectiveness. The romanticism in the art glorifies spirit of rebelliousness, the unique character of individual determined by his/her own experience. The art division into elite and democratic takes place.

It is possible to use the expression by I. Kant: "Minority is inability to make use of one's own understanding without direction ... [dare to be wise]. Have courage to make use of your own understanding!" (Kant, 1966, p.25-36) as the motto of social processes. The business is the social identifier. The development of machine production results in the fact that the dream "to rise above the crowd" means not only to have production means and use them at one's sole discretion, but also to have hired workers, i.e. to establish one's own "business". Production intensification processes prevailing in economy result in transformation of a hired worker into machine appendage, qualified labor importance decreases. Initially it provokes the competition among workers, rather than their unification in the struggle for their rights. As a result, female and children labor is used widely. However, further associations and strikes of workers pursuant to professional characteristic (smiths, stone masons, carpenters, printers, etc.) arise.

The role of state is the guarantee for realization of individual rights. Any person has the right to property that results from "use of abilities with which the nature endowed a human being, from occupation and work that give him/her possibility to make something to be his/her property" (Sagnac, 1928, p.35). The division of state power to legislative and executive ones takes place.

In result of Declaration of Independence of the USA in 1776 the two parallel existing political centers are formed - Europe and America in the world. In the letter by T. Jefferson dated 1813 the following characteristics of European-American relations is given: "The European nations constitute a separate division of the globe; their localities make them part of a distinct system; they have a set of interests of their own in which it is our business never to engage ourselves. America has a hemisphere to itself. It must have its separate system of interests, which must not be subordinated to those of Europe" (Jefferson, 1907, p.22). Portugal and Spanish colonies in Latin America gain independence. Five countries: Great 
Britain, Russia, Austria, Prussia and France decide the fate of Europe.

The growth of the positive influence of production scale (as a consequence of the scientifictechnical progress and widespread use of production means) results in adoption of factories, which activity base is vertical division of labor. The entrepreneurial activity is carried out according to the principle "supply produces demand" (Say, 2007). The major task of factories is productivity enhancement. The production process takes serial form. The invention of the universal heat engine allows the territorial location of production irrespective of the natural energy source. Enterprise enlargement takes place mainly in the form of reverse vertical absorptions. The machinery producing industry is thriving industry. It gives impetus to production concentration and urbanization.

\subsection{Conventional Stage}

The aspiration to stability is realized in the relativist worldview: not only struggle, but also unity of opposites that means use of compensations as the basis of social interactions and it manifests itself in the idea of equal opportunity. Things in existence are presented as dynamic unity of opposites characterizing by polarity of philosophy by F. Schelling (Schelling 1987). G. Hegel by means of dialectics substantiates the idea that thinking and reality are opposites that finds unity in essence of things (Hegel, 1997). The dialectical materialism by K. Marx and F. Engels demonstrates the implementation of equal opportunity idea as an attempt to unite materialism with dialectics by $\mathrm{G}$. Hegel: “... free development of each is the condition for free development of all” (Marks \& Engels, 1955a, p.447); only various abilities of individuals and "inequality of production carried out by them give reason to exchange and to their social equation to each other in exchange" (Marks \& Engels, 1955b, p.189). The realism prevails in art - the special attention is given to social relations through the prism of which an individual is examined.

The orientation to collective actions, coordination of interests of various parties: cooperative and associative movement in economic and social life, conventions in political life can be called the distinctive aspect of the social life. The joint forms of organization as a method to avoid the isolation of individual and his/her dissipation in the state are popular (Polanyi, 2006, p.22-29). Capital is the social identifier. Growth of scale of production and alienation of business owners from direct control over it, generalizing character of industrial transformations result in formation of the two classes: capitalists owing resources necessary for making a profit, and hired workers (irrespective of sphere of their employment).

The work movement takes organized form. In 1864 International Workers' Association was established that in $70^{\text {th }}$ years unites hundreds of thousands of members in France, Great Britain, Germany, Austria-Hungary, Switzerland, Spain. It stimulates governments of countries to ensuring social guarantees, extending rights and freedoms. The movement for abolition of slave trade takes the form of interstate agreement (the Quintuple Treaty between Great Britain, Russia, France, Prussia and Austria). In 1861 the serfdom is abolished in Russia. State is considered as the force contributing to consensus of various parts of society ensuring not only equal rights, but also equal opportunities.

The USA carries out the policy of expansion in the western hemisphere. Russia, on the one hand, 
Great Britain and France, on the other hand, take indirect part in the USA battle between the South and North. There is "discovery" by the USA of Japan that was in isolation accompanied with enforcing the peace and friendship treaty that provides the USA with the status of the most favored nation, and then conclusion of a series of treaties with Great Britain, France, Russia and the Netherlands. "Opium" wars and signing of unequal treaties of China with Great Britain, then with the USA and France take place. The North German Confederation is established. All these events are aimed to resistance of some countries to the rise of other ones - to support of the political equilibrium that contributes to interaction of countries in the two hemispheres and consolidation of international processes.

The further social-economic development of countries is hindered by relative separation of functioning economy sectors as well as by the strict protectionism policy. As early as in $1818 \mathrm{John}$ Calhoun stresses that each economy sector individually - industry, agriculture and trade - cannot become the basis for the social welfare (Calhoun, 1959, p.347). Only together they will be able to provide the prosperity. By the middle of XIX century active transformation begins in agriculture of many countries (in particular, in Great Britain, France, Russia); however, the greatest results were achieved in the USA. Except for Great Britain that implements the free trade policy, the rest countries adhere anyhow to protectionism. International economic relations are executed legally in the form of trade treaties (for example, France-Russia and Dutch-Russia 1846, Russia-Belgium 1850, Russia-Spain 1846, Russia-Portugal 1851, Russia-Denmark 1831). In the result of international trade the world market is formed with inter-industry subject specialization of countries.

The active cooperation of banking and industrial capital results in their integration - appearance of industrial-financial capital. The transformation of property forms takes place with alienation of owners from direct control over enterprises (share and associated capital). Cartels, syndicates are formed actively. The standardization covers practically all machine production fields, but meanwhile has intra-productive character. Therefore, corporations appear with large scale production and inter-regional scale of activity.

\subsection{Organizational Stage}

The hierarchical worldview determines social ordering processes: structuring as the method of society perception and one's place in it with aspiration to self-realization. In philosophy it is expressed the most strikingly in ideas of superman by F. Nietzsche " (1990a), man as microcosm and microtheos by N. Berdyaev (1995), conventionality of freedom and hierarchical structure of human psychics by S. Freud (2007). The cognition process loses impersonality: "Shouldn't discipline of scientific mind begin from the fact that you do not permit yourself any more convictions? Of course, probably so it is: it only remains to ask, should not be available conviction that this discipline could begin, in particular, such conviction is so imperious and unconventional, that other convictions are sacrificed" (Nietzsche, 1990b, p.344). The trend appears in art within the framework of which transfer of expression from object, but not only its image - impressionism is important. "Psychologism" trend appears in literature. The aspiration to self-realization of artists results in departure from academicism (cubism, futurism, surrealism and other trends). Art is divided into elite, mass and democratic. 
The process of social stratification covers society: middle class is formed from hired workers. The reputation being identified pursuant to title, name becomes the social identifier. The inherent worth of an individual and his/her personal responsibility for decision making is stressed. "Goodwill" term is used in economic practice as the advantage resulting from enterprise reputation (Leake, 1948). In 1891 after passage of laws about trademarks Madrid Agreement on international registration of factory marks and trademarks is signed individually in various countries.

The state administration apparatus is formed that is based on hierarchical bureaucracy, at that, the role of social life organizer is given to a state. The power structure is formed that consists of the three branches: legislative, executive and judicial. National ideas become actual: national culture, national self-consciousness at al. The transition from precedent legal regulation of social relations to formation of structural united national codes of law is completed. Monopolist formations in economy attain considerable influence that results in merging of political and economic power forms in society - state government at grown force and independence of private capital.

Germany and the USA demonstrate high temps of economic development and begin independent game on the world arena. As a result, redistribution of spheres of political and economic influence begins on the background of the completed territorial distribution. The result was World War I in which generally 34 of 56 countries existing at that time took part, and only the USA and Japan increased their national wealth. Anyway, Europe retains the leading role in international relations, but the USA begins to conduct active external policy, the peripheral role is assigned to Asia and Africa. The political regime is changed in Russia and Germany, Austrian-Hungarian and Turkey empires are disintegrated.

The mass production technology is realized in economy that on the background of overproduction determines processes of division of enterprises to leaders, followers and outsiders. Appearance of monopolist formation actualizes introduction of administrative managerial technologies and provokes deepening of the labor vertical division (high and middle management). Enterprise amalgamation takes place within the framework of holdings which activity covers the whole fields of national economy.

\subsection{Communication Stage}

The system outlook is manifested in the pursuit for self-improvement, which is possible only with the exchange interaction (cooperation), which requires openness of both an individual and the society). The correlation of Being and Existence in M. Heidegger (1949), the open and the closed society of H. Bergson (2010), the harmony between man and nature, an individual and society in E. Fromm (2008), synergetics in R. Buckminster Fuller (Fuller \& Applewhite, 1975). There appear interdisciplinary areas in science: tectology, theory of systems, cybernetics. Art becomes differentiated and evolving towards the interaction of different cultures, combination of conventional and innovative techniques, the mixture of styles and genres to demonstrate the inseparability of the spectacle and the real environment (performance, happening), inclusion of mass culture items in fine art (pop art), multiculturalism (not just appeal to the Eastern culture by European authors as seen in Eastern poems by G. Byron, "Siddhartha" by H. Hesse), but also inclusion of works of different cultures in the treasury of world art). 
Remoteness of various social classes from each other requires to improve communication channels for coordination of interests and thus to overcome information asymmetry, therefore implementing the principle of ideological society by creating public organizations as a means of social control. A country becomes a factor of social identity. In the world, a person is identified as a citizen of a certain country, and a product or a company is identified in accordance with the producer country ("Made in Japan”).

The state is seen as the voice of public interest and guarantor of maintaining equal rights, opportunities and responsibilities for everyone. In socialist countries, the state bureaucratic management is separating from the society and monopolizes instruments of regulating the economy. In capitalist countries, the desire for lobbying certain economic interests with the help of public policy, which is implemented in the form of sponsorship of election campaigns, results in economic and political power vested into a small group of persons. These policy regimes can be classified as oligarchy. There is a gradual convergence of the two socio-economic systems: the socialist economy integrates elements of market economy (for example, the principles of economic accountability and cost recovery), and the capitalist economy develops the public sector.

International relations, formed by policies of the European countries, which did not take into account the international character of global development processes (resulting from international economic relations) led to World War II. As a result of the redistribution of spheres of influence between the countries the post-war political system of the world is characterized by gradual weakening of the opposition between the capitalist and socialist ideologies, improved interaction between countries, and understanding of the fact that it is impossible to operate in isolation from others. The international monetary system is introduced along with establishment of the International Monetary Fund and the International Bank for Reconstruction and Development. Another event of the period is establishment of the United Nations (1945), the competence of which extends to economy, politics, environment, and humanitarian affairs. Since 1948, international economic relations are governed by the General Agreement on Tariffs and Trade. Further development of international relations acquires a complex nature, affecting more and more countries, and various areas of public life. In 1976, the Group of Seven is created for the settlement of political and economic problems.

In economy, modification of the content of marketing activities can be observed, although the term was coined in the early XX century: a study of customer requirements and business environment conditions, and forecasting as the basis for entrepreneurship activities. Social responsibility becomes one of the principles of doing business. External economic effects become state-regulated. The importance of exchange transactions in operation of economic institutions brings on development of the concept of transaction costs. Integration of culture and business and commercialization of art take the stage. Production associations in the form of combines and complexes with divisional-based management structure producing differentiated products come into existence, and the scope of their activities becomes global-wide. 


\subsection{Strategic Stage}

Social processes take place under the influence of an individualistic worldview: the desire to create conditions of its existence (self-activation), based on a mission. Freedom of choice, in the context of which the person is making history, and history is making the person (Sartre, 2000), the right of individual choice as recognition of diversity (Lyotard, 1998), "ironic liberalism" (Rorty, 1989). The once distinct boundary between art forms is getting blurred. Art becomes more dynamic (for example, moving pictures drawn by K. Simonova in sand), interwoven with nature (such as sculptures made of grass by M. Roussel-Giraudy and $\mathrm{O}$. Eliasson's installations), so the viewer is immersed in the image of a transformed reality (fantasy style).

Lifestyle (culture) acts as the basis for social stratification, and thus the overall picture of society is seen as a mosaic (fragmented nature). The active use of information leads to the fact that social identity marker is now the image (brand): the man and the organization appear as the result of purposeful creation of an image of itself in the eyes of the public, which involves extensive use of the media. As a result, the information field is represented by information pieces-fragments, which are not united into a single entity. As noted by A. Toffler, "In fact, we live in a blip culture."(Toffler, 1999, p.277) The model of altruistic behavior is actively spreading in the society, and the institute of charity is shaped.

Lack of mobility and flexibility as a result of highly centralized hierarchical control systems neglecting the individual needs in the socialist countries led to the collapse of the socialist countries' bloc, thus symbolizing the end of ideological confrontation in the world. As a result, the picture of the world is made up of approximately 200 formally legal peer countries, differing from each other in territorial size, economic and military power. Integration assumes the nature of creating transnational institutions and international economic and political networks (clusters) with fixing the functional role of countries inside them. Overall in the global arena there are several administrative centers (except for international economic and political networks, they also include TNCs), so the current model of the world system can be classified as polyarchy.

The modern state is seen as a "state, endowed with a sense of "ego" (Wendt, 1999, p.198) with a unique identity, and as a design to shape reality, based on the principle of subsidiarity. The fragmentation of society contributes to the fact that different segments of the society have their own image of the state therefore developing political subcultures.

In economics, the prevailing structure of the organization is a conglomerate the activities of which are characterized by the following: a policy of diversified acquisitions, significant weight of intangible assets in total assets portfolio, a significant political influence in the world, the presence of its own organizational culture. However, businesses in the conglomerate are at different levels of development and have different speed of development. The division of labor in organizations is carried out in the strategic and operational directions. Science and business are united: in the structure of conglomerates large business interacts with small innovative firms. 


\subsection{Synthetic Stage}

Social life is defined by a holistic worldview: the harmonious unity of diversity is a purposeful predesignation for each subject of the society. As its prerequisites the following can be defined: the principle of holism formulated by J. Smuts (1926); the vision of the whole life instead of its fragment, without distinction between "I" and "world" Krishnamurti (2005). What is happening in the world is the result of the processes described by Pierre Teilhard de Chardin in the mid-XX century. "In the present time ... all parts of humanity penetrate each other and smelt together before our eyes into a single unit in spite of the tendencies for separation of these parts..."(Chardin, 1965, p.256)

Combining cultural diversity in society is only possible on the basis of a universal tool - the outlook, which assumes the unity of vision as the basis of the formation of the universal order. An ideological community becomes the marker of social identity, because one's belonging to it is not determined by the circumstances of life, but by the will of the individual, as opposed to situation with territorial citizenship.

The nature of functioning of the state is transformed in the direction of efforts focused on formation of an organic social solidarity (Durkheim, 1996) observing the principle of equivalence of individuals.

In the global economy, there are two equal management centers (Europe-America and Asia-Africa) with a strong mutual influence (shared governance) in the form of cross-links, which coordinate their policies and work within the framework of a three-tier structure heterarchy.

The economic organization is a territorial association of closed cycle enterprises with custom-based production based on the principle of complete interdependence. Enterprises within such association do not lose their individuality, while maintaining functional and structural features and so on; they have a clear functional purpose - which is why there is no point in competition. Understanding of the role of the individual's ability and education for the successful functioning of organizations leads to integration of the spheres of education and entrepreneurship. Such a complex association has certain political, social, economic and cultural functions and becomes a public institution (i.e. it generates a steady behavior pattern).

\section{Conclusion and Discussion}

The period under review (1656-2092) is the final stage of another process of globalization, which is more extensive in time and dates back to the XIII century BC, according to our assumptions, and the study of which is our next important goal. Role of the final stage implies a practical implementation (use) of the result of comprehensive adaptation of mankind during 3,500 years in the form of implementation of achievements in life through economic development. Such a perspective for considering this period explains the commercialization of all spheres of public life and the changing context of consumption - the 
formation of a "consumer society."

Given the fact that the period from 1656 to 2092 is related to the rapid development of economy, an incremental increase in the amount of innovation (diffusion curve) and simultaneous reduction in manifestations of economic cycles because of counter-cyclical policy of states (due to the desire for preemptive forecasting of future) should be observed. These phenomena were reported by other researchers giving them a different explanation (Glazyev, 1993).

Besides, economic development on the background of integration with other spheres of social life can explain actualization of information and knowledge in social processes of the XX century, which has been reflected in science through formation of such concepts as "information society," "technotronic society," "network society" and "knowledge society."

\section{Research Perspectives}

The concept of economic and social development introduced here shows a complete picture of economic life of the society in its connections to other aspects of human activity, allowing one to trace the naturally determined character of these changes. During the eight selected periods from 1656 to 2096, the scheme represented complication of economic entities in the course of globalization of social processes, which is the objective consequence of integration. However, there is no likeness in the development of economic and political entities observed, but differentiation against the background of universal trends, i.e. deeper specialization. This makes it necessary to change the approach to the analysis of social processes and phenomena (including economic ones). Considering the world economy as a holistic system, and given the principle of distributed control and cross-parallel connections, we should first select functional components. Then, based on their intended purpose, we should proceed to interpretation and evaluation of changes occurring at the level of nation-states and multinational corporations. Understanding of the future trends in development of global economy will enable us to form a set of requirements for modern businesses, national economies and international chains. The basis for the formation of a coherent structured picture of economic reality may be the approach presented in (Kaparulina, 2012 b) and "Evolution of an enterprise: a metaphoric approach" by I.Kaparulina.

This concept of development of economy and society is based on the domain-object world view, and therefore social changes obey universal laws of existence. This allows us not only to apply it for analysis of social changes over a longer period of time, but also to integrate into the overall picture of the evolution of existence.

\section{Acknowledgements}

I would like to show my gratitude to my parents, husband and daughter for their help and moral support. 


\section{References}

Belkin, V.A., \& Yahontov, S.P. (2011). Unconventional cycling theory: cyclical solar activity cycles and economic development. Voprosy economiki, 2(15), 57-65.

Bell, D. (1999). The coming of post-industrial society: A venture of social forecasting. Moscow: Academia.

Bentham, J. (1834). The Science of morality: in which the harmony and co-incidence of duty and self-interest, virtue and felicity, prudence and benevolence, are explained and exemplified (2 vols). Vol.1. London: Longman, Rees, Orme, Green, and Longman; Edinburgh: W.Tait

Berdyaev, N. (1995). Kingdom of the Spirit and the kingdom of Caesar. Moscow: Respublika.

Bergson, H. (2010). Two Sources of Morality and Religion (Les deux sources de la morale et de la religion). ( $\left.2^{\text {nd }} \mathrm{ed}\right)$. Translate from France. Moscow: KDU.

Blumer, H. (1984). Society as symbolic Interaction. Translation from English. Moscow: Moscow University Publishing.

Braudel, F. (2007). Material Civilization, Economics and Capitalism 15Th-18th Century (3 vols). Vol.1. The perspective of the World. $\left(2^{\text {nd }}\right.$ ed). Translation from English. Moscow: "Ves mir" Publishing.

Calhoun, J. (1959). The Papers of John Calhoun. Columbia, South Carolina: University of South Carolina Press.

Chardin, P.T. (1965). The Phenomenon of Man. Translate from France. Moscow: Progress.

Chizhevsky, A. L. (1924). Physical Factors of the Historical Process. Kaluga: 1-ya Gospolitografiya.

Chizhevsky, A. L. (1976). The Terrestrial Echo of Solar Storms. Moscow: Mysl.

D'Aleo, J. (2008). Ultralong Solar Cyvle 23 and Possible Consequences. ICE CAP, 25.05.2008. Retrieved from icecap.us/images/ uploads/solarcyclestory.pdf

Durkheim, E. (1996). The Division of Labor in Society. Moscow: Kanon.

Engels, F. (1952). Socialism: Utopian and Scientific. In Marks K., Engels F. Selected works. Vol.2. Moscow: Gospolitizdat.

Fourastié, J. (2001). The great hope of the XX century. Moscow: Nauka.

Freud, S. (2007). I" and "It. Moscow: Eksmo; Kharkiv: Folio.

Fromm, E. (2008). Escape from Freedom. Moscow: Akademicheskiy proekt.

Fuller, R. B., \& Applewhite E. J. (1975). Synergetics: Explorations In The Geometry of Thinking. New York: Macmillan.

Gelmolt, H. (1904). History of humanity. World History. Vol.7. Western Europe. Translated 
from German. St. Petersburg: Prosveschenie.

Glazyev, S.Y. (1993). The theory of long-term technical and economic development. Moscow: VlaDar.

Graves, C.W. (2005). The Never Ending Quest. Dr. Clare W. Graves Explores Human Nature. Santa Barbara, CA: ECLET Publishing.

Hegel, G. (1997). Science of logic. St. Petersburg: Nauka.

Heidegger, M. (1949). Existence and being. Chicago-Illinois: Henry Regnery Company.

Hobbs, T. (1989). Human nature. In Works in 2 vols. Vol.1. (pp. 507-573). Moscow: Mysl.

Jefferson, T. (1907). The Writings of Thomas Jefferson. Vol. 14. Washington, D.C.

Juglar, C. (1862). Des Crises commerciales et leur retour periodigue en France, en Angleterre, et aux Etats-Unis. Paris: Guillaumin.

Kant, I. (1966). The answer to the question: "What is Enlightenment?" 1784. In Works in 6 vols. (pp 25-36). Translated from German. Moscow: Mysl.

Kaparulina, I.M. (2012a). Evolutionary-synthetic direction of field-object concept of knowledge. In Paradigm shift in the economics of the 21st century: Proceedings of the International Scientific and Practical Conference. (pp. 228-232). Kiev: Taras Shevchenko National University of Kyiv.

Kaparulina, I.M. (2012b). The theory of evolution of the economy: field-object approach. In P.G. Pererva, O.I. Savchenko (Eds), Management, marketing and intellectual capital in the global economic space (pp.42-570). Kharkov: Virovets "Apostrof".

Kondratiev, N.D. (2002). The Major Cycles of the Conjuncture and prediction theory: Selected works. Moscow: Ekonomika.

Krishnamurti, J. (2005). Comments on life. From notes by J. Krishnamurti. Vol.1. Rostov-on-Don: Feniks.

Kuznets, S. (1930). Secular Movements in Production and Prices. Their Nature and their Bearing upon Cyclical Fluctuations. Boston: Houghton Mifflin

Lapkin, V.V. (2010). Global dynamics in a time of great upheaval: the conceptualization of the problem. History and Modernity, 1, 5-27.

Leake, P.D. (1948). Commercial goodwill: its history, value, and treatment in accounts. (4th ed.). London: Gee \& Company (Publishers) Ltd.

Locke, J. (1985). Oeuvre. (3 vols). Vol.1. Moscow: Mysl.

Lyotard, J.F. (1998). The postmodern condition (la condition postmoderne). Translate from France. Moscow: Institute of Experimental Sociology; St. Petersburg: Aleteya.

Maddison, A. (2005). Growth and interaction in the world economy: the roots of modernity. 
Washington: The AEI Press.

Marks, K., \& Engels, F. (1955a). Works. Vol.4. May 1846 - march 1848. (2 ${ }^{\text {th }}$ ed). Moscow: Political Literature Publishing House.

Marks, K., \& Engels, F. (1955b). Works. Vol.46. The original version of Capital. ( $2^{\text {th }}$ ed). Moscow: Political Literature Publishing House.

Modelski, G. (2005a). The evolution of Global Politics. Polis: Political researches, 3, 62-82.

Modelski, G. (2005b). The evolution of Global Politics. Polis: Political researches, 4, 124-142.

Montesquieu, C-L. (1955). Selected works (De l'esprit des lois 1772). Moscow: Gospolitizdat.

Nietzsche, F. (1990a). The Gay Science (La Gaya Scienza). In Works in 2 vols. Vol.1. (pp. 491-719). Moscow: Mysl.

Nietzsche, F. (1990b). Beyond good and evil. In Works in 2 vols. Vol.1. (pp. 238-405). Moscow: Mysl.

Pavlenko, I.M. (2011). Economic cycles and adaptation processes in the enterprise. In Business strategy: adaptation of enterprises to the effects of global socio-economic processes. International scientific and practical conference. (pp. 55-57). Kiev: KNEU.

Podlesny, S.V., Erfort, Y.O., \& Iskritsky V.M. (2004). History of engineering. Kramatorsk: DDMA.

Polanyi, K. (2006). On faith in economic determinism In R. Nureev (Ed.), Great Transformation K. Polanyi: Past, present, future. (pp 28-37). Moscow: GU-HSE.

Rorty, R. (1989). Contingency, irony, and solidarity. New York: Cambridge University Press. http://dx.doi.org/10.1017/CBO9780511804397

Rostow, W.W. (1960). The Stages of Economic Growth: A Non-Communist Manifesto. Cambridge: Cambridge University Press.

Rousseau, J-J. (1970). On the causes of inequality. Anthology of World Philosophy in 4 vols. Vol 2. Moscow: Mysl.

Sagnac, F. (1928). Civil legislation French Revolution (1789-1804). Translation from France. Moscow: Kom. Akad. Publising.

Sartre, J.-P. (2000). Being and Nothingness: The experience of phenomenological ontology. Translate from France. Moscow: Respublika.

Say, J-B. (2007). A Treatise on Political Economy. Moscow: Direct-Media.

Schelling, F. (1987). Works in 2 vols. Vol.1. Translate from German. Moscow: Mysl.

Schumpeter, J. A. (1939). Business cycles: A Theoretical, Historical and Statistical Analysis of the Capitalist Process. New York-Toronto-London: McGraw-Hill Book Company. 


\section{Macrothink}

Research in Applied Economics

ISSN 1948-5433 2013, Vol. 5, No. 3

Smuts, J.C. (1926). Holism and Evolution. New York: The Macmillian Company. http://dx.doi.org/10.5962/bhl.title.4568

Sokolov, V.V. (1969). Anthology of World Philosophy in 4 vols. Vol.1. Ancient and medieval philosophy. P.1. Moscow: Mysl.

Toffler, A. (1999). The third wave. Translate from English. Moscow: Publishing house "AST".

Vladimirovsky, B.M., Temuryanth, N.A., \& Martynuk, V.S. (2004). Space weather and our lives. Fryazino: Vek 2.

Wendt, A. (1999). Social Theory of International Politics. Cambridge: Cambridge University Press. http://dx.doi.org/10.1017/CBO9780511612183

Xie, J., Korniss, G., Sreenivasan, S., Zhang, W., Lim, C., \& Szymanski, BK. (2011). On the Influence of Committed Minorities on Social Consensus. Physical review, E, Statistical, nonlinear, and soft matter physics, 84, 1-15 (32).

Zhukov, E. (Ed.) (1958). World History. Encyclopedia. Vol.5. Moscow: Publisher socio-economic literature.

\section{Copyright Disclaimer}

Copyright reserved by the author(s).

This article is an open-access article distributed under the terms and conditions of the Creative Commons Attribution license (http://creativecommons.org/licenses/by/3.0/). 